\title{
Assesment of Stakeholder Participation as Criterion for Sustainability of Community Based Public Health Projects in Western Kenya
}

\author{
BARASA Ramadhan Makokha ${ }^{1}$, MUKANZI Clive Malietso ${ }^{2} \&$ NYANG’AU Samson ${ }^{2}$ \\ ${ }^{1} \mathrm{PhD}$ Student, Jomo Kenyatta University of Agriculture and Technology, Kenya \\ ${ }^{2}$ Lecturer, Jomo Kenyatta University of Agriculture and Technology, Kenya \\ Correspondence: BARASA Ramadhan Makokha, PhD Student, Jomo Kenyatta University of Agriculture and \\ Technology, Kenya, HD417-c009-0558/2015.
}

Received: June 1, 2021 Accepted: July 31, $2021 \quad$ Online Published: October 20, 2021

doi:10.5430/jbar.v10n2p57 URL: https://doi.org/10.5430/jbar.v10n2p57

\begin{abstract}
Community based projects are the basis for sustainable socio-economic development of most nations in the developing world. Consequently, such projects should be planned and designed to benefit communities over a long period. In Kenya, existing literature indicates that most of these projects don't stand the test of time. Incidences of projects stalling soon after commissioning have been reported in many parts of the country. It is in this vain that as events unfold, organizations and institutions are integrating the principles of sustainability in project management in order to ensure projects serve the communities for a long time as envisioned. This study was carried out in Western Kenya. It assessed the role of stakeholder participation in the sustainability of community based public health projects. Funding was considered as a moderating variable. The study adopted descriptive survey design. A sample of 360 respondents was purposely sampled from of a population of 5570 committee members of various public health facilities. Data was sourced through questionnaires, interview schedules, and document analysis and observation checklists. Data was analyzed both descriptively and inferentially. The computations for correlation on the influence of stakeholder participation on sustainability was at value $r=0.713$, with a coefficient of determination at 0.508 . This translates to $50.8 \%$, of change in project sustainability is attributable of stakeholder participation. ANOVA was at $\mathrm{R}$ value of 0.901 , implies $81.2 \%$ of change in sustainability could be explained by stakeholder participation. Further, the rate of change, computed at $\mathrm{Y}=0.945 \mathrm{X}+5.648$, implied positive change, at rate of 0.945 between the two variables. Consequently, the study recommended, that for public health projects to sustainably serve communities, players must adopt stakeholder participation, amongst others parameters in project design, planning and sustainability.
\end{abstract}

Keywords: stakeholder participation, sustainability, integrated management, moderation and funding

\section{Introduction}

Globally, more than 1 billion people live in extreme poverty with income inequalities prevalent in many countries (UNO, 2013). At the same time unsustainable consumption and production patterns have resulted in huge socio-economic and political costs which continue to pose an existential threat to mankind. People continue to plunder resources without consideration of the consequences. However, if Nations adopt the tenets of sustainable development as espoused in the Brundtland commission report, 'Our common future' which advocates for utilization of resources, cognizant of the fact that future generations will require the similar resources, then the likelihood of curbing this challenge becomes a reality. To achieve sustainable development on global scale, the United Nations Organization (UNO) has come up with several protocols and charters that includes the Millennium Development Goals (UNO, 2000) and the Sustainable Development Goals (UNO, 2015). In the context of this study, project sustainability is very crucial in the economic, social and even political development. It is in this vain that, development strategies should entail the activities that are cognizant of the role of stakeholders which ensures sustainability.

On average sustainability and project management issues motivate studies that seek to focus on development of sustainable projects (Martens, 2016). For instance, donor agencies like the World Bank undertake international development projects but rely on partners for implementation and longevity hence the need to incorporate the principles of collaboration (Ika, 2012). Furthermore, critical project success factors comprise; monitoring, 
coordination, design, training and project environment, which call for involvement of all players, hence stakeholder involvement (Ika, 2012). It is important to note that successful projects focus on efficient time management, cost effectiveness, appropriate objectives and relevance to intended impact and stakeholders (Ika, 2012). In Kenya, Vision 2030, the country's blueprint for economic development that envisions Kenya as middle income economy by 2030, is anchored on sustainable development principles. It is in this vain that project management must incorporate sustainability principles, amongst which entail the involvement of stakeholders.

\subsection{Statement of the Problem}

In Kenya, more than $40 \%$ of the projects stall soon after commencement with initial funding from the project financiers (Savaya, 2008). Such projects have less impact on the communities they are meant to serve (Person, 2016). When projects are not sustainable the consequences are far reaching. There are normally unsolved issues, amongst which is failure to consider the role of stakeholders (GOK, 2014). In the developing world, there is an increasing dependence on foreign aid in the medical sector, which currently it stands at $25 \%$ (GHR, 2017). According to GHR, (2017), the cost can go up to 10,000 USD which makes it very unaffordable for most people, like the population in Western. Generally, medical care is met through insurance or individual paying at a cost, which most people in the communities cannot afford (GHR, 2017). Therefore, it is imperative that communities access affordable health care, lack of which results into negative demographic trends that includes: high mortality rates and poverty; inaccessibility to education; and poor nutrition. It is therefore desirers to establish the criteria for sustainability of community health projects using project management practice tools. Such tools comprise, amongst others, the genuine involvement of stakeholders as equal partners (Adam \& Omer, 2015). Ultimately, sustainability of health facilities: reduces the reliance on foreign aid for medical services; improves standards of living; and income generation in the communities (Githinji, 2013).

\subsection{Objective of the Study}

This study assessed stakeholder participation as a criterion for sustainability of community based public health projects in Western Kenya. Specifically, it focused on the role of stakeholder participation in the sustainability of public health facilities. It further appraised funding as moderating criterion of sustainability for community based public health project in Western Kenya. The study was premised on the hypotheses, thus,

$\mathbf{H o}_{1}$ : Stakeholder participation does not have significant influence on sustainability of community based public health facilities.

$\mathbf{H o}_{2}$ : Funding does not have a moderating effect on sustainability of community based public health projects in Western Kenya.

\subsection{Conceptual Framework}

Conceptual frame provides the structure of content for the whole study based on literature. According to Kombo \& Tromp, (2009), a conceptual framework of a study depicts the relationship between independent variables and dependent variables often expressed diagrammatically, Figure 1. It acts as a link between the literature, methodology and the results (Voughan, 2008). Figure 1 is conceptual framework showing the link between the independent variable, stakeholder participation, dependent variable, sustainability and the moderating variable, funding. In this study, indicators of stakeholder participation comprise: level of involvement; integrated project management; decision making; and stakeholder analysis and their contribution to sustainability. 


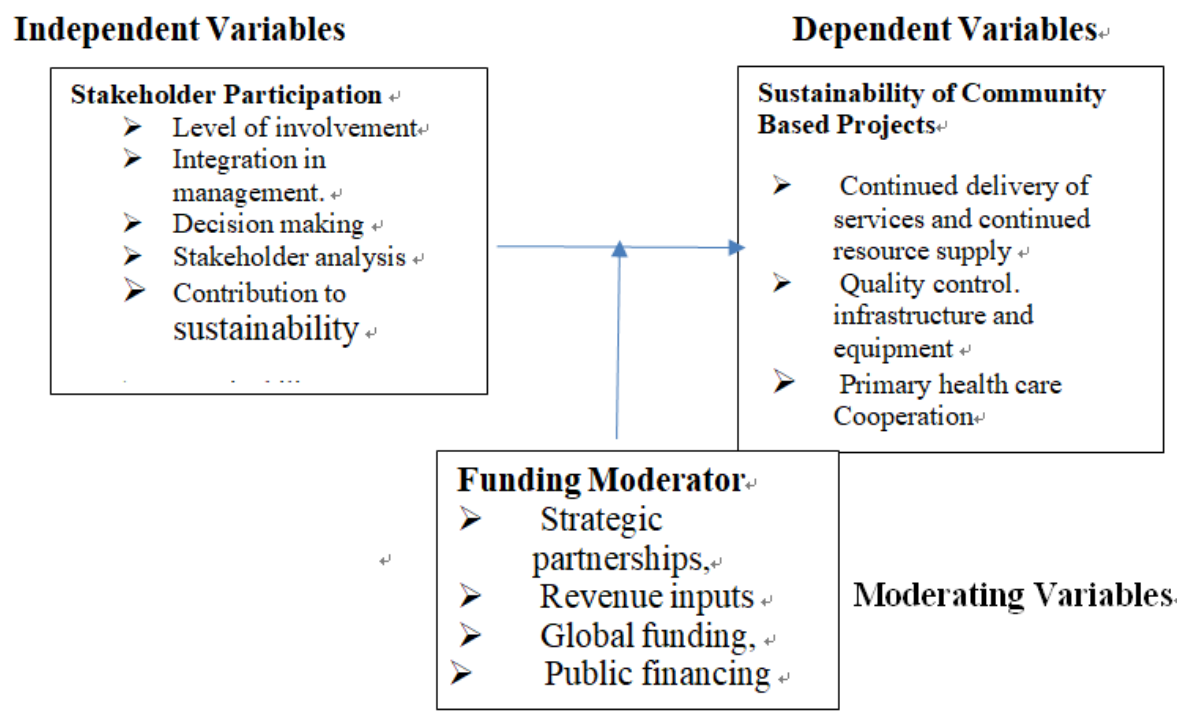

Figure 1. Conceptual Framework

\subsection{Literature Review}

Stakeholders are an integral part of corporate social institution and play a significant role in sustainability of an institution. Often stakeholders are either affected or affect the achievement of the project objectives. For instance, they may relate with the project as; shareholders, customer's, supplier's, distributor's, members of local communities and employees.

In pursuant of project sustainability, participation design and implementation of projects contributes significantly to the sustainability development activities (PAI, 2007). Stakeholders provide opportunity to influence public perception and a positive tone. Engaging with stakeholders from the initial stage enables proactive cultivation of relationships that can serve as capital during challenging times in the life cycle of the project. For instance, they can influence project selection which is among key components that avails: the direction of project sustainability; the selection of projects; and programs of work are key functions of both public and private sectors of organizations (IFC, 2007). Selection of a project should be based on tangible and intangible criteria by experts and stakeholders who are the decision makers (Saat, 2009). (Bobrow, 2014) observes that a project can only be sustainable if it addresses amongst others, the needs of the stakeholders, now and future generations (Bobrow, 2014).

Therefore, sustainability of community based project requires participatory approach that entails stakeholder participation. Effective project management requires analytic and intensive skills to identify stakeholders as they enable the project management team to comprehend stakeholder priorities and needs. It strengthens stakeholder commitment, ownership and willingness to share costs (Jones, 1995). It generates an opportunity for social learning and innovations borrowing from their experience. The attendant impact is increased efficiency and effectiveness of services. Indeed extensive engagement with stakeholders contributes to policy change and improve stakeholders access to decision making process (Bolt, 2011).

\section{Methodology}

The study adopted descriptive survey design which enabled the researcher to collect quantitative data from respondents at relatively low cost and quickly. Data was analysed both descriptively and inferentially. This allowed for a more central coverage of the research process and possible generalization of research findings about the general population vide the sample findings (Saunder, et al., 2007). It requires a target population which is well defined, like in this present study.

\subsection{Target Population}

Target population comprised of a total of 5570 committee members including: public health professionals' staff and stakeholders of public health facilities as key informants in their various capacities. Key Informants were the Ministry of Health officers and other stakeholders (GOK, 2014). Ministry of health officials were targeted because they coordinate and direct management of the health facilities on the behalf of the Government. 


\subsection{Sampling Techniques.}

Purposive sampling was used. This enabled the researcher to arrive at various categories of respondents as observed by Mugenda \& Mugenda, (2003). A total of sample ( $\mathrm{S}=$ sample size of 360 ) was used in the study.

\subsection{Data Collection Instruments}

Instruments of data collection comprised, questionnaires, interview schedules, observation checklists and document analysis. The respondents were accorded an opportunity to answer questions and give their views in line with the theme of the study. A triangulation of collected information was done through focused interviews. Pilot study was done to pre-test validity and reliability of research instruments.

\subsection{Data Collection Procedure}

A pilot study was carried out in Siaya County to pre-test a questionnaire for its reliability and validity, after the initial design and formulation. Primary data was collected from targeted project committee members using self-administered standardized questionnaires. Secondary data was sourced from document analysis, journals and published theses. Both primary and secondary data collected was cleaned by identifying the errors and eliminating them. It was then coded and analyzed systematically.

\subsection{Data Analysis and Presentation}

Data was collected and analyzed both descriptively and inferentially. Inferential analysis is one of the methods that are used to make generalizations, estimate and make predictions from data. The statistics are used to describe systems of procedures that can be used to draw conclusions from data analysis (Freeman italic., 2010). Hypothesis testing was done using SPSS at 5\% level of significance. Data was presented using tables, graphs and charts.

Correlation coefficient was used to measure extend to which independent variable is related to dependent variable. According to Kothari, (2008), correlation analysis is used to establish simple partial and multiple correlations. The researcher analyzed and worked out the significance of estimated relationships using SPSS. Further, regression analysis was used to determine whether an independent variable predicts a given dependent variable. The relationship can either be positive or negative (Kothari, 2008). Further, the coefficient of determination $\left(R^{2}\right)$ which is a measure of degree of linear association or correlation between two variables, independent variable and dependent variable was determined. The coefficients were worked out to show relationship between variables.

\section{Results and Discussion}

The objective of the study was to assess the stakeholder participation as a criterion that influences sustainability of community based health projects in Western Kenya. The results are discussed hereunder following the areas of interest as: descriptive statistics, tests of hypothesis, correlations, regressions and ANOVA.

\subsection{Response Rate}

A total of 360 questionnaires were given to the respondents who were committee members at specific public facility and stakeholders at the public health facility. There was a return rate of $100 \%$. According to Mugenda and Mugenda (2012) a return rate above 70\% response is acceptable. Distribution of respondents per County, sample size and the various health facilities was done.

\subsection{Demographic Information}

The main demographic parameters considered in this study were the educational levels of the respondents as summarized in Table1.Most of the respondents were professional medical staff. 
Table 1. Education Level of the Respondents

\begin{tabular}{lcc}
\hline Qualifications & F & $\mathbf{\%}$ \\
\hline Others & 14 & 3.9 \\
Diploma & 7 & 1.9 \\
Bachelors degree & 175 & 48.6 \\
Post-graduate & 170 & 47.2 \\
Total & 360 & 100 \\
\hline
\end{tabular}

From Table 1, it is evident that the respondents had adequate education, most had above diploma certification that enabled them to respond to the issues put to them and also, perform their duties and influence sustainability of the health facilities. Specifically, the education levels are as detailed in Table 1, hereunder: Post graduate, 170; bachelors, 175, Diploma, 7 and others unspecified 14.

Table 2. Role of Stakeholder Participation in project Sustainability Likert scale values.

\begin{tabular}{ccccc}
\hline & & Valid \% & Cumulative \% & Likert Scale interpretation of \% \\
\hline Valid Valid Valid Valid & Very low & 4.2 & 4.2 & 0.2 \\
& Not sure & 2.3 & 6.5 & 0.12 \\
& High & 40.7 & 47.4 & 2 \\
& Very high & 51.3 & 59.0 & 2.55 \\
& Missing in system & 1.5 & 100 & 0.13 \\
Total & & 100 & 5 \\
\hline
\end{tabular}

Table 2 shows the responses on how they respondents viewed the role of stakeholders in the sustainability of the public health facilities. Most them had a mean of more than 4 on Likert scale, within a maximum of 5 . Basing on a maximum of 5, all of them scored high and above a mean of 4.55 it is a measure of the center of gravity and standard deviation of more than 0.5 . This implies that the respondents considered stakeholders as playing a pivotal role.An average of $51.3 \%$ indicated that stakeholder participation influences sustainability of public health facility. Respondents expressed the importance of stakeholders and the important role they play in project sustainability. For instance, they expressed impact of projects that involve stakeholders benefit from resources such as funding, development of infrastructure and engagement of human resources with requisite skills and knowledge. In addition, stakeholders form part of the supply chain that ensures project sustainability PAL, (2007).

The findings affirmed that they have stakeholders who give financial support to the facility, in Table 2 a total of $92 \%$ indicated high or very high on Likert scale. The respondents agreed that they were involved in capacity building and had effective support of collaborator

A total of $91.7 \%$ respondents observed that the stakeholders should form an integral part of the public health facilities. They emphasized the need for priority to projects that address their needs. The findings are congruent with a study by PAL, (2007), that observed the critical role played by stakeholders. Most of the stakeholders were staff of the facility. They include doctors, clinical officers, nurses' trainee medical staff and community leaders. They were involved in decision making and perform professional duties in line with government policy. Findings showed stakeholder participation influence project sustainability. However, there were indications of overreliance on government and donor funding. It is important for communities to participate in functions especially in the devolved governance so that the country achieves vision 2030 .

Findings indicate that stakeholders significantly influence project sustainability. Specifically, the stakeholder roles included; planning, as part of management, funding, projects formulation and implementation, amongst others. 87\% of respondents in Figure 2 affirmed the influence of stakeholders. Standard deviation of 2.58820 shows that stakeholder participation has significant influence on sustainability of a health project. 
Figure 2 shows of how stakeholder participation influence to the project. The distribution leads to the same conclusions as the descriptive summaries in Table 3. The results depict a slight nonsymmetrical distribution of the stakeholder participation influence to the project with a slightly rightward skew about the mean, a minor deviation from the normal curve. The distribution stakeholder participation does not appear to have outliers among the respondents. The figure shows the predicted values of stakeholder participation in project sustainability. From the figure, stakeholder participation influences the sustainability of a project. When stakeholders work as a team the benefit are enormous they articulate the interests of the community with more depth of understanding of their needs.

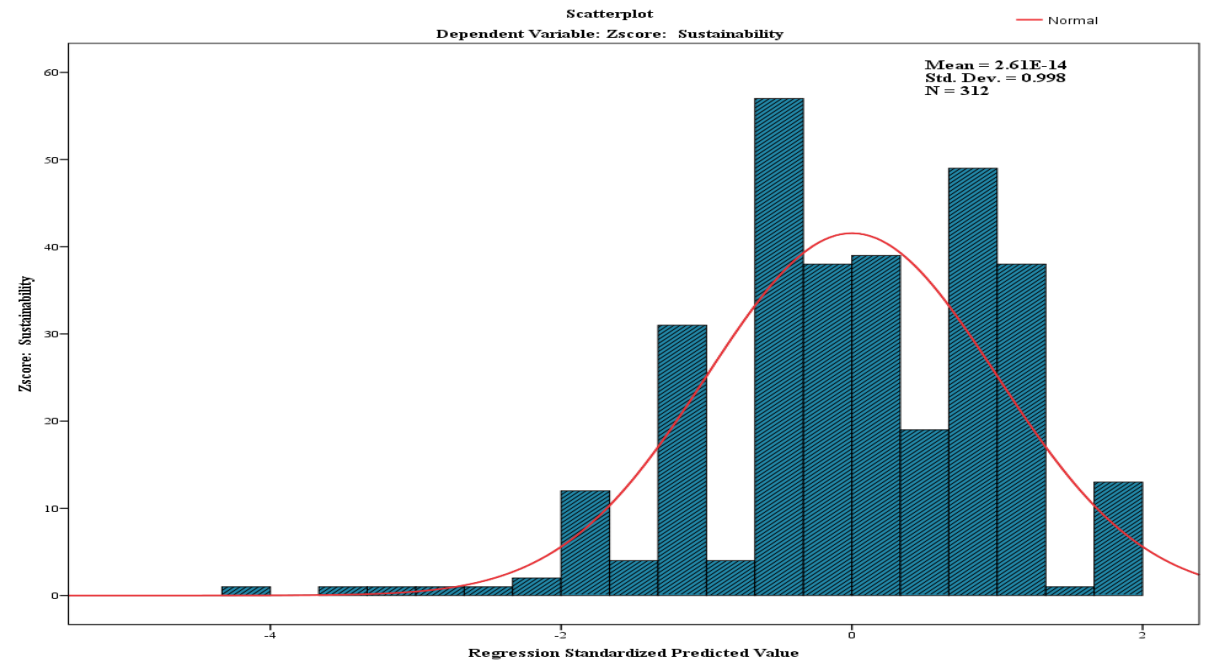

Figure 2. Standardize z Values for the Stakeholders Participation

\subsection{Descriptive Analysis of Dependent Variables Considered in the Study}

This section deals with descriptive analysis of dependent variables. It comprises of details of the analysis and actual findings of the study. The following sub-variables were used to determine the dependent variables, thus, the role of stakeholders in: continued service delivery by a health facility; rating primary health care in their health facility; infrastructure and equipment, services delivery and cooperation on sustainability as considered hereunder

\subsection{Extent of Continued Service in the Health Facility}

Table 3 refers to continued service over a long period of time. Fifty-four percent $(54.5 \%)$ of the respondents indicated that the continued service in the health facility was high. The respondents indicated that well-managed facility can be sustainable, hence continue to avail service to the community. That can only be achieved through cooperation between the National and County Governments.

Table 3. Rating of Continuity of Health Facility and Service Delivery

\begin{tabular}{llccc}
\hline \multirow{6}{*}{ Valid } & & Frequency & Percent & Cumulativssse Percent \\
& Very low & 4 & 1.0 & 1.0 \\
& Low & 10 & 2.9 & 3.9 \\
& Not sure & 4 & 1.0 & 4.9 \\
& High & 139 & 38.5 & 44.3 \\
& Very high & 196 & 54.5 & 98.8 \\
\hline Missing & System & 7 & 2.2 & 100 \\
Total & & 360 & 100.0 & \\
\hline
\end{tabular}


Table 3 shows a total of $54.5 \%$ of the respondents noted the importance of continued service delivery and the strategic role county health service plays. Most of the respondents appreciate that the Government has ensured continued service in their medical facilities. Further, for continued provision of health care services, respondents recommended home care services. According to Oketch (2016), the Government should focus UHC by investing in infrastructure and enhancing access to health facilities. For example specialized medical equipment and personnel to operate the equipment. It requires policy to ensure prioritized and sustainable development.

\subsection{Rating of Primary Health Care}

The respondents indicated that primary health care is critical as indicator of sustainability of health service delivery. It is direct service to the people in the community which is at the grass root. Primary health care is the hope of everybody in the community that is why more than $90 \%$ supported. The expressed at the Key informants' discussions that patients get frustrated when they are sent away because health facility equipment and tools are no longer serviceable or not functional resulting in referrals of patients to county hospitals.

\subsection{Infrastructure and Equipment}

Infrastructure and equipment are critical for sustainability of a public health facility. A total of $97 \%$ of the respondents indicated that there was need to have high quality of infrastructure and equipment these would impact on the sustainability of the said facility. This would curtail reliability on referral services for treatment of our patients in hospitals. Referrals of patients to other hospitals due to lack of simple diagnostic tools in the institution can be highly reduced.

\subsection{Extent of Continued Service Delivery by a Health Facility}

The cornerstone of sustainability is availability of good facilities and continued service to the community. Good performance and quality staff is critical. Patients visit a facility that is appropriately equipped and with good services.

From the discussions with the respondents, $55 \%$ recommended home-based care for patients who are not critically ill. This would: reduce the burden on the infrastructure and human resources; reduces cultural shock; and improves on sustainable health care. Home care is an opportunity for continuity of health services to the community. However, they further indicated that the home-based care requires: a link between the hospital and home care personnel; deliberate policy that is well legislated by government showing role of the community; and medical staff. With the advent of the COVID-19 pandemic, the home-based care came into operation by the pressure that presented as the existing health facilities could not cope. It is now a Government policy to nurse less critical patients at home. It is saving lives of patients of law level COVID 19 and thousands of patients have recovered through home based facilities.

\subsection{Cooperation on Sustainability}

Cooperation is an aspect of stakeholder participation, between National Government and County Government influences sustainability. In the current devolved governance, medical staff engaged by the county government. Nonetheless, there is a pivotal role played by the national government. For instance, donor funding from WHO or Global Fund is channeled through the national government. Consequently, there is need for cooperation between the two tiers of governance. The aforesaid can positively impact on the sustainability of the health facility. Therefore, cooperation is amongst the critical function of dependent variables.

\subsection{Inferential Analysis}

In this study the inferential analysis was used to determine the relationship between independent variable, stakeholder participation, moderator, funding and dependent variable sustainability include correlation, regression and ANOVA. Financing was considered as the moderating variable in the research. Inferential analysis is one of the methods that was used to make generalizations, estimate and make predictions from data. The statistics are used to describe systems of procedures that were used to draw conclusions from data analysis (Freeman ita., 2010). In this study the inferential analyses used to determine the relationship between independent variable, stakeholder participation, moderator, funding and dependent variable sustainability using correlation, regression. The following are the parameters considered under inferential analysis: normality tests correlations regressions and ANOVA.

\subsection{Normality Test for Collinearity}

It is a test using a sample of independent observations of the null hypothesis, Normal distribution within variables $\mathrm{S}^{2}$ and mean. It is tested using z-values. The Tables present the results from two tests of normality, thus, the test utilized Kolmogorov-Smirnov Test and the Shapiro-Wilk Test. The test for normality was developed by Andrey Kolmogorov and Nikolai Simirnov in1933 (Arnold \&Emerson, 2011) the assumption is that residuals are normally distributed and 
therefore can be used for data distribution in the variables (Emerson \& Arnold, 2011). From the Tables 4 and 5 presence data from research findings that is basically residual hence the conclusions therein. The results depict high rejection of Null hypothesis stakeholder participation explains more than $50 \%$ of change in sustainability of health project.

Table 4. Tests of Normality: Stakeholder Participation.

\begin{tabular}{llllllll}
\hline \multirow{2}{*}{ To what extend Stakeholder participation influence project } & \multicolumn{3}{l}{ Kolmogorov-Smirnov $^{\mathbf{a}}$} & \multicolumn{3}{l}{ Shapiro-Wilk } \\
\cline { 2 - 7 } & Statistic & Df & Sig. & Statistic & Df & Sig. \\
\hline Very Low & .272 & 9 & .054 & .805 & 9 & .024 \\
Low & .256 & 7 & .182 & .833 & 7 & .086 \\
High & .373 & 153 & .000 & .654 & 153.000 \\
Very high & .389 & 122 & .000 & .661 & 122.000 \\
\hline
\end{tabular}

Table 5. Model Summary Durbin.Watson

\begin{tabular}{|c|c|c|c|c|c|c|}
\hline \multirow[b]{2}{*}{ ModelR } & \multirow[b]{2}{*}{$\begin{array}{l}\text { R } \\
\text { Square }\end{array}$} & \multirow[b]{2}{*}{$\begin{array}{l}\text { Adjusted R } \\
\text { Square }\end{array}$} & \multirow[b]{2}{*}{$\begin{array}{l}\text { Std. Error of the } \\
\text { Estimate }\end{array}$} & \multicolumn{2}{|c|}{ Change Statistics } & \multirow[b]{2}{*}{ Durbin-Watson } \\
\hline & & & & $\begin{array}{l}\text { R Square } \\
\text { Change }\end{array}$ & $\begin{array}{ll}\text { F } & \text { Sig. F } \\
\text { Change } & \text { df1 df2 } \\
\text { Change }\end{array}$ & \\
\hline 1 & .508 & .506 & .37147 & .508 & 320.0831310 .000 & 1.805 \\
\hline
\end{tabular}

The model summary in Table 5 show the strength of the relationship between the model and the influence of independent variables. For $r=0.713$, the coefficient of determination is 0.508 , which means that $50.8 \%$ of the variations in project sustainability can be predicted from the relationship between the linear combination of independent variables and project sustainability the results stakeholder participation influences sustainability of public health facilities. Durbin -Watson analysed sequence of observations and noted that they can be analysed using multiple regression.

\subsection{Correlation Analysis}

Correlation analysis refers to statistical relationship involving dependence, used in the analysis of variables and can be used for detecting more general dependencies (Ngaira, 2016) In the study Pearson moment correlations as used as well p-values showing degree of significance between variables (Mugenda \& Mugenda, 2012). Correlation was done to determine the relationship between the predictor and predicted variables.

Correlation was used to analyze the degree of relationship between stakeholder participation and sustainability of health facilities. Further, the F test in Tables was used to determine the significance of the correlation between the variables: stakeholder participation, funding and sustainability of the health facilities.

The mean and standard deviations were used for analysis of project sustainability in comparison to extend to which health facilities benefit from stakeholder participation. Additionally, a comparison of the standard deviation shows that the extent to which health facilities benefit from stakeholder participation is more spread in comparison to project sustainability. Stakeholders are extensively involved in project sustainability.

Table 6. Stakeholder Participation Model Summary

\begin{tabular}{lllll}
\hline Model Summary & & & \\
\hline Model & $\mathrm{R}$ & R Square & Adjusted R Square & Std. Error \\
1 & $.901^{\mathrm{a}}$ & .811 & .811 & 1.02696 \\
\hline
\end{tabular}

a. Predictors: (Constant), stakeholder

Table 6 shows R coefficient of .901 is $<1$ that shows rejection of Null hypothesis. The results are consistent with 
earlier results. Similarly, other values are consistent with the other results Table 6 for example B of 0.945 that is stakeholder participation can influence sustainability of health facilities at rate of .945 of in change in sustainability of facilities. The stakeholders see themselves positively about project sustainability.

$\mathrm{F}$ test was used to determine the significance of the relationships between the variables in the study. Findings in Table 6 showed a positive and significant influence of stakeholders on sustainability of health facilities. For example, stakeholder $r+0.901$ shows influence of $81 \%$ on sustainability is very high and null hypothesis of $0.000<.05$ shows that stakeholder participation has significant effect on sustainability. From the findings, there is growing interest in project sustainability by stakeholders. Stakeholders participate in planning, implementation and execution of health projects, hence involved in sustainability of the project. The respondents who were mostly staff members expressed deep commitment to health institutions. The sustainability of the institutions offers them directly livelihood. The model: shows the strength of the relationship between the model and the extent of stakeholder participation influence project. Table 7 shows the coefficient of determination is 0.901 , which means that $81 \%$ of the variations in project sustainability can be predicted from the relationship between the extent of stakeholder participation influence project and project sustainability.

Respondents expressed their strong position in sustainability of health projects. The study supports research done by Bobrow (2014) that the facility has to address the needs of stakeholders. Table 5 shows the influence of stakeholder and summarizes the residuals and predicted values produced by the model. The results are consistent with research work done by Guther and Ingeborg, (2005). Emphasis was on team work by communities' and management of the health facilities, there is growing interest in project sustainability by stakeholders.

\subsection{Regression Analysis}

Regression is a measure of relationship between variables. The study carried out a regression by fitting linier regression for the data analysis. It was used to determine the nature of the relationship between predictors and predict and (Opiyo, 2013). The study carried out regression analysis to establish the statistical significance relationship between predictors and predict. These are stakeholder participation and funding. The regression of each predictor in relation to the predictand that is sustainability and results discussed. The coefficient of determination $\mathrm{R}$ square was used as a tool to determine the proportion of variance, predictors and predictand. He results of regression analysis were presented using scatter plots, regression models, model summaries and Analysis of variance (ANOVA) as detailed in Tables 7

Analysis of variance (ANOVA) was done. This entails analysis to determine the significance of the relationship between stakeholder participation and sustainability of the project. The result showed significant relationship. The tables show clear consistency and relationships. The Table 7: shows that the extent to which health facilities benefit from stakeholder participation predict as a predictor and the project sustainability at value $\mathrm{F}(1231.730, \mathrm{p}<.0005$ The interpretation is that the regression of stakeholder participation on sustainability significantly improves the ability to predict the extent to which health facilities benefit from stakeholder participation. This is based on the fact that ANOVA value at 0.00 shows stakeholder has significant influence on sustainability of health projects.

Table 7. ANOVA Regression and Residual Values

ANOVA $^{\mathrm{a}}$

\begin{tabular}{lllllll}
\hline Model & & Sum of Squares & Df & Mean Square & F & Sig. \\
\hline 1 & Regression & 1755.138 & 1 & 1755.138 & 1231.730 & $.000^{\mathrm{b}}$ \\
& Residual & 424.632 & 298 & 1.425 & & \\
& Total & 2179.770 & 299 & & & \\
\hline
\end{tabular}

a. Dependent Variable: Sustainability

\subsection{Hypothesis Testing}

The study had the hypothesis; $\mathrm{Ho}_{1}$ : stakeholder participation does not have influence on sustainability of community based public health projects. Tables, 9 show the analysis. The Beta value of $0.897<($ Beta $<1)$ and B of 0.945 test of significance of 0.000 , show rejection of null hypothesis implying the predictor, in this case stakeholder has influence on the predicted, here being sustainability of the health facilities. The R value of 0.901 and square of 0.801 implies 
stakeholder has a role to play to the extent of $81.1 \%$ of in predictand. Table 9 on regression of stakeholder participation, it gives value of $\mathrm{R}^{2}=0.8112=$ that is $81.2 \%$ of Sustainability is due to stakeholder participation the rest can be explained by other variables. Similarly, Tables shows 0.000 significance that implies high rejection of Null hypothesis.

Here, a regression analysis was done to establish significance of relationship between stakeholder participation and sustainability it was established that it was significant, thus stakeholder participation the hypothesis is states that $\mathbf{H o}_{2}$ : Stakeholder participation does not have significant influence on sustainability of community based public health projects is rejected. Tables 8 and 9 were used to plot figures 3 and 4 on regression of stakeholder's participation on sustainability of public health facilities. R value of 0.945 shows influence by stakeholder participation can be explained. Similarly implies $81.2 \%$ of change in sustainability can be explained by stakeholder participation. The results show rejection of Null hypothesis most of the respondents were stakeholders they were proud of the role they play in the sustainability of medical facilities.

Table 9. Residual Statistics Stakeholder Participation

\begin{tabular}{llllll}
\hline & Minimum & Maximum & Mean & Std. Deviation & N \\
\hline Predicted Value & 11.3189 & 24.5508 & 22.2100 & 2.42281 & 360 \\
Residual & -5.71538 & 3.17488 & .00000 & 1.19171 & 360 \\
Std. Predicted Value & -4.495 & .966 & .000 & 1.000 & 360 \\
Std. Residual & -4.788 & 2.660 & .000 & .998 & 360 \\
\hline
\end{tabular}

Table 8. Stakeholder Participation Coefficients

\begin{tabular}{|c|c|c|c|c|c|}
\hline \multirow{2}{*}{ Model } & \multicolumn{2}{|c|}{ Unstandardized Coefficients } & \multirow{2}{*}{$\begin{array}{l}\text { Standardized Coefficients } \\
\text { Beta }\end{array}$} & \multirow{2}{*}{$-\mathrm{T}$} & \multirow{2}{*}{ Sig. } \\
\hline & $\mathrm{B}$ & Std. Error & & & \\
\hline (Constant) & 5.648 & .477 & & 11.843 & .000 \\
\hline Stakeholder Participation & .945 & .027 & .897 & 35.096 & .000 \\
\hline
\end{tabular}

Tables 8 and 9 were used to plot scatter graphs figures 3 and 4 Regression equation: Predicted variable (dependent variable $)=$ slope $*$ independent variable + intercept $(\mathrm{Y}=\mathrm{aX}+\mathrm{b})$

$\mathrm{Y}=0.945 \mathrm{X}+5.648$

In Table 9, stakeholder participation residuals statistics are assumed to be normally distributed that were used to derive the equation. The equation can be used for working out sustainability from stakeholder participation values. For example, 1 unity change in stakeholder participation will translate to sustainability unity of 0.945 . Figures 3 show strong positive regression between stakeholder participation and sustainability. The stronger the stakeholder participation the more the sustainability. 


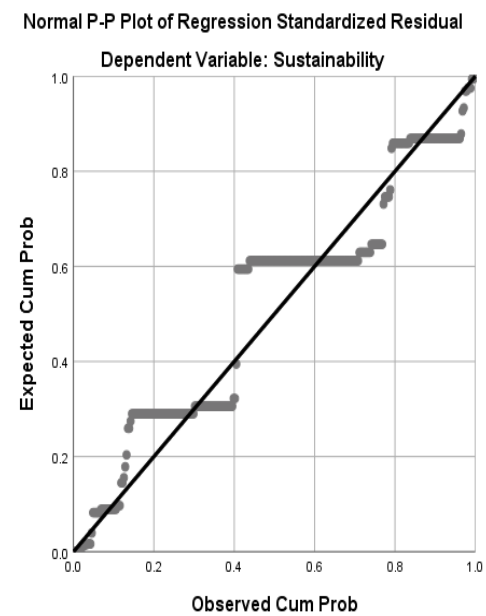

Figure 3. Normal P-P Plot of Regression Standardized Residual Dependent Variable: Sustainability

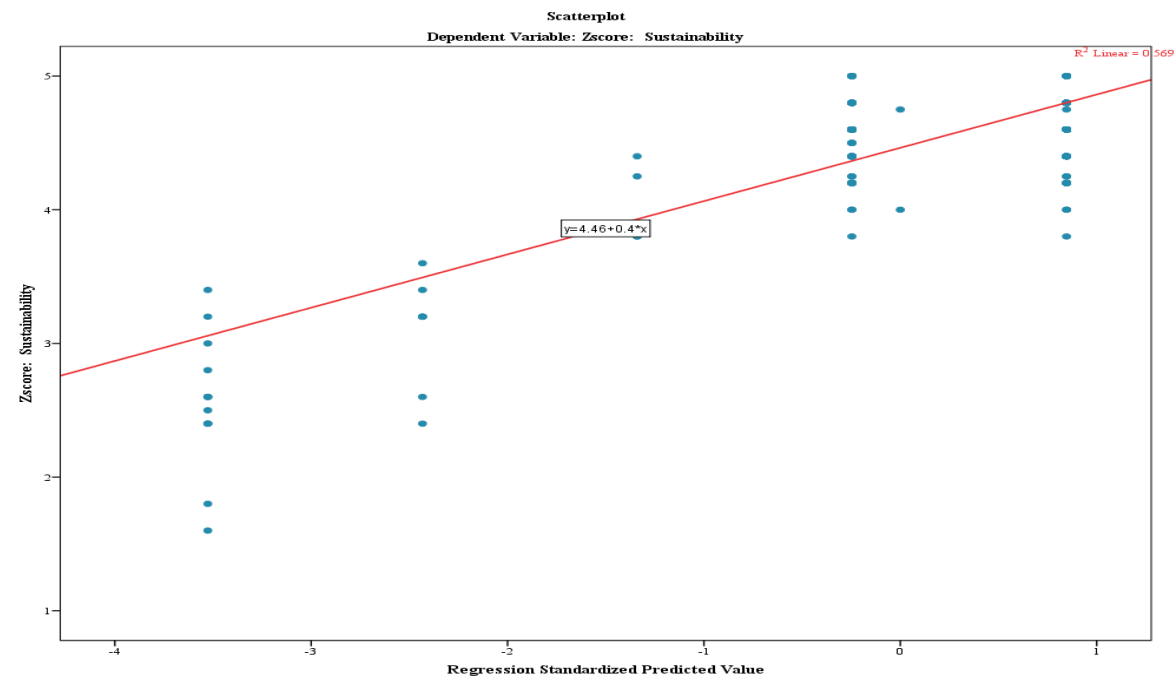

Figure 4. Scatter Plan for Stakeholder participation

\subsection{Funding}

Leedy and Ormrod (2013) examined practical research planning and design and concluded that moderating variables influence the nature, strength and relationship between independent and dependent variable. It may reduce or increase the cause and effect relationship between the variables, thus moderating the effects sustainability of a project. Funding is one of the variables that influence criteria for sustainable community based projects. According to Leedy \&Ormrod (2013), it entails the act of providing resources, amongst which are financial. According to Marek, (2007), funding involves availing finances for a particular purpose, whilst strategic funding is availing funds on long term basis hence an aspect of continuity is crucial. It can be through Government agencies or from investors who are interested in the project as an investment (Leed \& Ormrod, 2013).

Effective financing plan should involve informed decision making by analyzing projected resources and needs that includes fiscal and non-fiscal resources (Gager, 2014). Clearly defined funding sources and financing strategies are critical to fill the gaps among the strategies. To boost funding, it is necessary to build public and private partnerships which positively creates additional flexibility in existing funding sources. Sustainable financing need must be ensured across sectors including agriculture, forestry, energy, health and education as well as across economic segments that include small and medium size enterprises (Economic survey report, 2015).

Riggs (2012), examined strategies of sustaining grand funded projects and observed that sustainability funding 
requires identification of short term and long term sustainability strategies; and assessment of the project; and identify resources that need to be sustained involving committee members and strategic partners; identification of most successful programmers used for grant startup; and look upon the community or other sources for long term sustainability (Riggs, 2012). This ensures resource enhancement by developing new dedicated revenue inputs that have plans and resources in place for present and future programing ongoing mechanisms to secure funding. Overall, sustainability funding ensures the viability of an ongoing project. It therefore requires effective planning and proper financial management together with understanding of what is funding and income opportunities available (Bucks, 2015).

3.15.1 Funding as Moderating Factor in Project Sustainability

Table 10. Sources of Funding for the Health Facilities

\begin{tabular}{lcc}
\hline & YES (\%) & NO \\
& & $(\%)$ \\
\hline Central Government & 73.1 & 26.6 \\
County government & 68.2 & 31.8 \\
NGO & 40.3 & 59.7 \\
World Bank & 39.0 & 64.1 \\
Harambee (local fund raisings) & 49.0 & 50.6 \\
CDF & 27.6 & 72.4 \\
Global funding & 78.6 & 21.4 \\
Public financing & 45.4 & 54.6 \\
UNEASCO & 53.6 & 46.4 \\
\hline
\end{tabular}

The respondents' observations on various questions put to them regarding funding are as detailed in the Table 10

From Table 10, it is evident that most of the health facilities draw their funding resources from the Central Government as indicated by at $73.1 \%$ of the respondents; followed by County Governments as indicated by $68.2 \%$. Global fund stands out as the main source of foreign funding. From the respondents, this is a funding from the United States of America, used mainly in family planning and management HIV and AIDS. Further, when asked to what extent they thought funding was an important moderator for project sustainability, $78.6 \%$ respondent positively, see table 5 responded in the affirmative.

From the foregoing, it is evident that project financing is a very crucial entity in the sustainability of public health facilities. This a component that should always be considered and must be properly managed. Indeed, records in the observation checklists attest to the fact that some health facilities had stalled due to improper management of funds.

\subsubsection{Regression of Moderating Variable, Funding}

Riggs (2012), examined strategies of sustaining grand funded projects and observed that sustainability funding requires identification of short term and long term sustainability strategies; and assessment of the project; and identify resources that need to be sustained involving committee members and strategic partners; identification of most successful programmers used for grant startup; and look upon the community or other sources for long term sustainability (Riggs, 2012). This ensures resource enhancement by developing new dedicated revenue inputs that have plans and resources in place for present and future programing ongoing mechanisms to secure funding. Overall, sustainability funding ensures the viability of an ongoing project. It therefore requires effective planning and proper financial management together with understanding of what is funding and income opportunities available (Bucks, 2015). 
Table 11. Model Summary of Moderating Variable Funding

\begin{tabular}{ccccc}
\hline Model & $\mathrm{R}$ & $\mathrm{R}$ Square & Adjusted R Square & Std. Error of the Estimate \\
1 & $.911^{\mathrm{a}}$ & .830 & .829 & 1.11258 \\
\hline
\end{tabular}

a. Predictors: (Constant), Funding

b. Dependent Variable: Sustainability

Tables 11 showed a positive and significant influence of funding as moderating variable of health facilities. For example, funding $\mathrm{r}$ value is 0.911 is very high and null hypothesis of 0.000 shows that funding has significant effect on sustainability. Funding can change the project positivity or negatively. Regression was done and found to have a significant effect. Beta value of .911 (Beta $<1$ ) shows accepting alternative hypothesis it is strong relationship between funding and Sustainability of Public Health Facilities. R of .911 means R $^{2}$ of 0.83 thus $83 \%$ of sustainability can be explained by funding.

The model Table 12 indicates the strength of the relationship between the model and the influence of global funding for sustainability of your facility. For $B 0.784$, which means that $78.4 \%$ of the variations in project sustainability can be predicted from the relationship between the global funding influence sustainability in a facility and relationship between the global funding influence sustainability in a facility and project sustainability.

Results and Tests on influence of funding as a moderating variable, Null hypothesis is rejected. The respondent emphasized the role of Funding of projects either by the Government or donor.

Regression equation: predicted variable (dependent variable $)=$ slope $*$ independent variable + intercept $(\mathrm{Y}=\mathrm{aX}+\mathrm{b})$ $\mathrm{Y}=0.784 \mathrm{X}+5.348$

Table 12. Funding Moderating Variable

\begin{tabular}{lllllll}
\hline \multirow{2}{*}{ Variable -Funding } & $\begin{array}{l}\text { Standardized } \\
\text { Coefficients }\end{array}$ & $\mathrm{T}$ & Sig. & \\
\cline { 2 - 6 } & $\mathrm{B}$ & Std. Error & Beta & \\
\hline 1 & (Constant) & 5.348 & .446 & & 11.989 & .000 \\
\cline { 2 - 4 } & Funding & .784 & .021 & .911 & 38.194 & .000 \\
\hline
\end{tabular}

\section{Conclusions and Recommendations}

The objective of study was to assess stakeholder participation as a criterion for sustainability of public health projects. Details on the Likert scale show the strength of influence stakeholder participation influences sustainability of health projects. The study confirms that involving stakeholders in the operations and management of health facilities plays a crucial role in their sustainability. Stakeholders should be involved in initiation fisibility studies implementation and management which includes M\&E of the operationalized facilities. Stakeholders should be involved in planning, execution, implementation, operations and management of projects. The greater the engagement of stakeholders in project activities the stronger the sustainability. Most of the stakeholders are part of the workforce, community members, and those drawn from M\&E domain.

The findings from correlation and regression depict strong influence of stakeholder participation on sustainability of public health projects. The results of study show that stakeholder participation is significant and positively related to sustainability of public health facilities. Stakeholders should have requisite knowledge to qualify to be part of management and policy making of health facilities.

Regarding financing as a moderating factor, it was observed that this had a very crucial role in the sustainability of the health faculties. In the contemporary scenarios, there is evidence that the funding of health facilities in Kenya, has been devolved and is now being carried out by the county governance. However, the remittances form the exchequer are not adequate to meet the needs at county level. Consequently, the country experienced strikes in the health sector attributable to failure by the county governments to meet the needs of the health staff and even provide proper infrastructure.

Due to the aforesaid findings, this study recommended that public health facilities should establish leadership 
structures that are easy to understand. Leadership structure should include hospital stuff, Ministry of health and stakeholders. Should adopt dynamic and transparent management system. Management have levels of authority but creative and innovative especially establish virtual network with stakeholders which is essential for quick decision making. The results of study show that stakeholders role significant and positively related to sustainability of public health facilities. The Government, the stakeholders and the health facility have stakes and benefits in such institution.

Focus should be on management and virtual functionality of system. Assist in capacity building of the staff, equipping health institutions should be part of the role of stakeholders. Financing functions by stakeholders can enhance sustainability. Cooperating with other departments will contribute to sustainability.

From the findings of this study, it was observed that funding as a moderating factor had a very crucial role in the sustainability of the health faculties. In the contemporary scenarios, there is evidence that the funding of health facilities in Kenya, has been devolved and is now being carried out by the county governance. However, the remittances form the exchequer are not adequate to meet the needs at county level. Consequently, the country experienced strikes in the health sector attributable to failure by the county governments to meet the needs of the health staff and even provide proper infrastructure.

\section{References}

Anita, W. (2017). Foundation of sustainability development. Kakamega Kenya. Kenya. Retrieved February 18, 2017, www.fisdinternation.org

Arnold, B., \& Emerson, W. (2011) Nonparametric Goodness-of-Fit Test Tests for Descrete Null Distributions. The Review Journal, 34, 39. https://doi.org/10.32614/RJ-2011-016

Bobrow. (2014). Sustainability marker to support project selection process. Publisher UNOPS-Ricardo Viana Vargas. www.ricardo-vargas.com $>$ article $>$ sust

Bolt, R. (2011). Stakeholder engagement framework department of education and early child development. Published by the department of education early childhood development Melbourne Australia. Leute.com>word press $>2011 / 107 / 25$. A critical research review. Journal of information technology, 2(3). 133-146.

Cosimo, R., Nikola, R., \& Cesare, Z. (2013). Sustainable food supply chains. The role of collaboration and sustainable relationship. International Journal of Business and social science, 4(4).

Economic Survey Report 2015, GOK technology. (2015). Wellinngton: Ako Ao rearoa National center for tertiary teaching excellence.

Freeman, R. E. (2001). Stakeholder approach to strategic management. SSRN Electronic Journal Dol, 10(2635), 21-39. https://doi.org/10.2139/ssrn.263511

Freeman, E., Harrison, J., Wicks, A., Parmar, B. L. I., \& Colle, D. E. (2010). Stakeholder theory, the stake of the art Cambridge University press published in USA. NEW YORK: Cambridge University press. https//www.stakeholder map.com>stake

Ghazala, M., \& Rao, V. (2003). Evaluating community - based and community - Driven development. Driven development. A critical review of the evidence. September, 2003 site resources. worldbank-org $>$ Dec study

Githinji, C. M. (2013). Factors affecting sustainability of community based projectsa case study of Mutomo District of Kitui County. Nairobi. D53 / ol / 14838/2009. Retrieved February 6, 2016

GHR. (2017). Global health care resources published by Global medicine resources in partnership with international resource centre. Retrieved on December 252017

GOK. (2007). Vision 2030 Popular Version. Nairobi:published by Government Printers.. www.vision2030.go.ke $>$ lib $>\mathrm{f}=$ =vision-2... Retrieved December 10, 2016.

GOK. (2009). Population census. Kenya National Bureau of statistics.Published byKNBS Nairobi. , 12, 2016. https://www.knbs.or.ke>category>

GOK. (2014). Kenya National Bureau of statistics population census.Published by KNBS Nairobi. 12, 2016. https/www.knbs.or.ke/kenya-population and housing census.

Gray, B., \& Sites, J. P. (2013). Sustainability through partneship capitalizing on Collaboration.Published by Pennyslyvania: Pennslyvania state university. www.theguardian.com/sustainable-business/paul-polmanuniliver-sustainable-living-plan. Retrieved February 16, 2016. 
Gunther, B., \& Ingeborg, N. (2005). National strategies towards sustainable development. The impact of councils in European sustainable development sustaining sustainability. Published by Aberchimark study on the German council for SD.www.nachnaitigkitstratdequentherbachmann@nachhati gkeitguatide.

Hobrow, T. (2014). Executive ChairmanNexagure Group pte/Linkedin. Whittington Group pte Ltd, Singapore, HongKong and Bankok. Sg.Linkedi co>tony-hobrow-221

IFG. (2007). Measurable development impact and continud gowth. International Financecooperation.www.IFC.org $>$ ifc $>$ wps $>$ wcm $>$ connect. Retrieved February 6, 2016

Ika, L. A. (2012). Relationship between critical success factors. published by world bank projects and project success. International Journal of project management, $30(2012), \quad$ 105-116. https://doi.org/10.1016/j.ijproman.2011.03.005

Jones, S. P., Reed, R., \& Skinner, B. H. (2001). Sustainable hand pump projectsin Africa. WEDC publications Loughborough University, UK Leicerster shire LEII 3 TU UK.

Katajano, K. (2016). Guidelines for programme design monitoring and evaluation (176, 00161). Published by department for development policy, Helsinki, Finland.

Kombo, D. \& Tromp, L. (2009). An introduction Proposal and thesis writing; Pauline publications Africa, Nairobi.Scholargoogle.com>citations. International journal of science education, 23(3) 281-302

Kothari, C. R. (2004). Research methodology methods \& techniques age (2nd ed., pp. 1-2). New age international publisher.

Kothari, C. R. (2008). Quantitative techniques: Book 3rd edition published by vikas publishing House PVT LTD. Reged office 576 masjid road jangpura new delhi - 110 014. Retrieved from https//www.health.org. 2014/08

Leedy, P. D. \& Ormrod, J. E. (2016). Practical research planning and design. Retrieved from www.sreporebook.com>book>practical. Retrieved June 13, 2016.

Marek, I., \& Mancini, J. A. (2007). Sustaining of community based programmes.Published by Virginia: Virginia polytechnique institute and State university Blacksburg.

Martens, M, L. \& Caivalho, M. M. (2016). Factors of sustainability in project management context. International Journal of project management. PMA, 01876.

Matron, J. (2013). The future off sustainabiility. Published byCambridge: IUCN. https://doi.org/10.1680/foen.16.00026

Mugenda, O., \& Mugenda, A. (2004). Reseearch methods.: African center for technology studies Nairobi, Kenya. American Journal of education research, 2(114), 30-38

Mukanzi, C. M., Gachunga, H., Ngugi, K., \& Kihoro, J., M. (2014). Leadership and worlif balance: Perceived managerial supoort as a moderator between burnout stress, absentism and emplyee commitement. Journal of leadership managemnent.

Murray, A. (2011). Governance of projects making strategy reality. Published by white paper prince 2 and governance document number 2(1042-10-101), 1-21 research, 2,757-768.

Omer, A. (2015). The cry of the Forgoten Stones, Wiley online Library. The promise and the limits of Palestinian Liberation Theology, as a method for peace building. Journal of Religious Ethics, 369-407. https://doi.org/10.1111/jore.12101

Opiyo ,E. (2013) ,Effects of corporate governance on insider trading. Prime Journal of Business Administration and Management, 3(10), (1202-1224)

PAI. (2007). Project administration instructions implementing small projets with community participation. Retrieved from www.adb.org/sites/ default/files/

Person, L. (2016). Factors influencing the sustainability of community based programs: a mixed method study faculty of health medicine and life sciences. Maastricht University 16017081, 07-02-2016.

Riggs, K. (2012). Strategies for sustainability of grant funded programs. Utah state university. Retrieved September 9,2016

Sander, G., Stephen, J., Senn, J., \& Alman, D. G. (2008). Statistical tests, P values confidence intervals and power, a guide to misinterpretations. European Journal of Epidemology, 2008(31), 337-350. 
https://doi.org/10.1007/s10654-016-0149-3

Scandelius, C. \& Cohen, G. (2016). Sustainability program brands: platforms for collaboration Industrial. Markma management salum, 57(2016), 166-176. https://doi.org/10.1016/j.indmarman.2016.02.001

Schlegal, S. (2016). Johanesburg embrace sustainable plan - UN - Habitat. Retrieved from https://unhabitat.org $>$ johannesburg

Shut, C. (2011). Monitoring, evaluation and Assessing, the impact of Governance programmes. Retrieved December $8,2017$.

Susskind, L. (2001). Communicative planning in action, planning theory creating innovative cities and regions. CRPLAN 2110.

Krie madis T. \& Theakou, E. (2007). Strategic planning in public and nonprofit sector organization, department of sport management university of Peloponnese smd. 13(2) 2007.

Saunders, M. Lewis, P., \& Thornhill, A. (2007). Research methods for business students. USA, New York, prentice Hall: Pearson Education.

Savaya, R., Spirro, S., \& Bara, E. R. (2008). Sustainability of social programs a comparative of social programs: A comparative case study analysis. American Journal of evaluation, 29(4), 478-493. https://doi.org/10.1177/1098214008325126

Sunday, C. E. (2016). The role of theory of research. Published by university of the WESTERN CAPE. Retrieved from https://www.uwc.ac.za7 documents

Tafara, A. C. (2013). Factors influencing sustainability of rural community based water projects in Mutito Andei, Kibwezi Subcounty, Kenya. Retrieved September 15, 2016.

Thapa, G. (2009). Sustainability of rural development project. Asia and Pacific region. (EASSDA). European Journal of Business and social sciences, 5(07), 2016.

UNDESA. (2012). Sustainable development in Kenya. Stock taking in the luk up to Rio +20 , Nairobi Kenya, Retrieved from http/www.nation.co.ke

UNO. (2007). Indicators of sustainable development guidelines and methodologies. U.N.O.

UNO. (2003). Millennium development goals- website United Nations \{Millennium> declaration. New York. Retrieved from www.Undp.Org $>$ home $>$ mdg-goals

UNO. (2013). World economic survey. New York: United Nations. Retrieved August 11, 2016.

UNO. (2015). Sustainable development goals (SDGs). Sustainable development summit New.

UNO. (2000). Millenium development goals. New York: UN.

UNO. (2016). Integrating BIG DATA into the monitoring and evaluation of Development programmes. Published by Rockefeller foundation integrating big data - intomedp - web - UNGP

UNO. (2013). Internal and External environment analysis. New York: UN. Retrieved August 11, 2016, from www.un.org/en/peacekeeping/news/yiR2013.shtml.

Vaughan, R. (2008). Conceptual Framework. Published by Bournemouth University. Retrieved On January 26, 2017. The internet and higher education, 11(34), 133-136. https://doi.org/10.1016/j.iheduc.2008.06.003

Vaughan, R. (2008). Conceptual Framework Established By Bournemouth University.

Zander, B., \& Busse, R. (2017). Improvement on health system performance. Biomedcentral Europe. Retrieved, April 30, 2017, from https//health-polic-systemsbiomedcentral.com

\section{Copyrights}

Copyright for this article is retained by the author(s), with first publication rights granted to the journal.

This is an open-access article distributed under the terms and conditions of the Creative Commons Attribution license (http://creativecommons.org/licenses/by/4.0/). 